\title{
Naturally Occurring Intrauterine Growth Retardation and Adult Blood Pressure in Rats
}

\author{
LORI L. WOODS AND DOUGLAS A. WEEKS \\ Division of Nephrology and Hypertension [L.L.W.], and Department of Surgical Pathology [D.A.W.], \\ Oregon Health \& Science University, Portland, OR 97239
}

\begin{abstract}
In humans, infants who are born small have been reported to have higher blood pressure in adulthood than do larger infants. This suggests that factors in the intrauterine environment that affect fetal growth can program the individual for hypertension later in life. The present study determined whether there is a similar, naturally occurring relationship between birth weight and adult blood pressure in rats. Female Sprague-Dawley rats bred in our colony were fed a normal diet during pregnancy. On the day of delivery, any pups that weighed $<90 \%$ of the mean pup weight for the litter were identified as runts. For each runt, a sex-matched littermate of normal weight was also identified and assigned to this study. These pairs were chronically instrumented at $\sim 20$ wk of age. Mean arterial pressure was significantly higher in runt male and female offspring compared with their normal birth weight littermates (males: $149 \pm 7$, runts
\end{abstract}

\section{ABSTRACT}

versus $129 \pm 4 \mathrm{~mm} \mathrm{Hg}$, controls; females: $128 \pm 1$, runts versus $119 \pm 2 \mathrm{~mm} \mathrm{Hg}$, controls). Although the runts had smaller body weights at study than did their littermate controls, the kidney-tobody weight ratio and renal function normalized to kidney or body weight were not different. These studies indicate that adult blood pressure is related to birth weight in rats, as it is in humans. The relative hypertension in runt animals is not due to gross differences in renal function but may be related to more subtle renal structural and/or functional differences. (Pediatr Res 56: 763-767, 2004)

\section{Abbreviations}

ERPF, effective renal plasma flow

PAH, para-aminohippurate
Epidemiologic studies in humans have reported that there is an inverse relationship between fetal growth and the risk for many adult diseases, including ischemic heart disease and hypertension (1-5). Thus, full-term infants who are born smaller have an increased risk for cardiovascular disease in adulthood compared with larger infants. This suggests that factors in the maternal environment that affect fetal growth can permanently change the structure and function of specific organ systems in the offspring, thus setting a trajectory leading to disease later in life.

Although the physiologic and morphologic mechanisms responsible for this perinatal programming are not well understood, we and others have developed animal models of this phenomenon that have begun to allow examination of mechanisms. For example, maternal dietary protein restriction, global

Received April 20, 2004; accepted June 15, 2004.

Correspondence: Lori L. Woods, Ph.D., Division of Nephrology and Hypertension, L463, Oregon Health \& Science University, 3181 S.W. Sam Jackson Park Road, Portland, OR 97239-3098; e-mail: woods1@ohsu.edu

These studies were supported by grants R01HD041074 and P01HD34430 from the National Institute of Child Health and Human Development, HL070132 from the National Heart, Lung, and Blood Institute, and a Grant-in-Aid from the American Heart Association (all LLW)

DOI: 10.1203/01.PDR.0000142589.08246.77 food restriction, and maternal dexamethasone injection all have been shown to produce offspring that have reduced birth weight and are hypertensive in adulthood (6-10). We have postulated that these treatments may cause offspring hypertension as a result of impairment of nephrogenesis and a consequent reduction in the nephron endowment, and several studies have supported this hypothesis (11-14).

Poore et al. (15) reported that mean arterial pressure in pigs was inversely related to birth weight. To our knowledge, no other studies have examined whether animal offspring of naturally occurring low birth weight have higher blood pressure than those of normal birth weight that were exposed to the same maternal environment. The purpose of the present study was to determine whether naturally occurring small-forgestational-age rat offspring have increased blood pressures compared with their normal littermates and, if so, to examine a possible role for the kidney in this hypertension.

\section{METHODS}

All procedures on animals were approved by the Institutional Animal Care and Use Committee. Female SpragueDawley rats (Simonsen) that weighed $\sim 250-300 \mathrm{~g}$ were bred at Oregon Health \& Science University. As part of our ongoing 
studies of perinatal programming in the rat, the pregnant animals were maintained on a normal protein (19\%), normal $\mathrm{Na}^{+}(0.20 \%)$ diet (Purina 5755) ad libitum throughout pregnancy and lactation. At birth, litters (11 total) with "runts" (defined here as pups of low birth weight, $>10 \%$ below the mean for the litter, average of $20 \pm 2 \%$ below the mean) were identified. Thus, the runts were naturally occurring small-forgestational-age animals. (In our laboratory during the period of this study, $20 \%$ of all litters born to dams on this diet had one runt, and another $10 \%$ of the litters had two runts.) In each case, the runt and a sex-matched littermate control were assigned to the present study. This study design has the advantage that each pair of pups was exposed to the same maternal environment. In general, pups were paired prospectively. In cases in which adult data were eventually available for more than one control, the control with the highest blood pressure (which would bias against the hypothesis) was used. Pups were weaned to the above normal diet and maintained on that diet until instrumentation at $19 \mathrm{wk}$ of age. Immediately before surgery, 24-h urine collections were done on the animals for determination of protein excretion.

Surgical preparation of adult animals. The animals were surgically instrumented as described previously (7). Briefly, under ketamine/xylazine/acepromazine anesthesia, a stainless steel silastic-covered catheter was inserted into the bladder and Tygon catheters were implanted into the left femoral artery and vein. The animals were allowed to recover for at least $6 \mathrm{~d}$ before any experiments were conducted and were maintained on the normal diet. For acclimatizing them to the study conditions, the animals were placed in a wire restrainer in the study room for at least $2 \mathrm{~h}$ on at least three different days before study.

Experimental protocol. Blood pressure and renal function were measured in conscious animals as described previously (7). With the rat in a wire restrainer in a quiet study room, urine was allowed to drain continuously through the bladder catheter. Between 0600 and $0900 \mathrm{~h}$, mean arterial pressure was measured through the arterial catheter, and a reading was taken after at least $30 \mathrm{~min}$, when the pressure had stabilized. GFR and effective renal plasma flow (ERPF) were measured as the clearances of inulin and para-aminohippurate (PAH), respectively, in a series of four successive 20-min urine collections (clearance periods), with a blood sample taken at the midpoint of each. After centrifuging the blood, the plasma was frozen at $-20^{\circ} \mathrm{C}$ and the red cells were resuspended in an equivalent volume of saline and returned to the animal.

When all experiments were completed or when the instrumentation was no longer functional, the rats were killed with a commercial euthanasia solution. Kidneys and other tissues were removed immediately, weighed, and prepared for histopathology as described below.

Analytical measurements. Inulin (16) and PAH (17) in plasma and urine were assayed after deproteinization of the plasma with zinc sulfate. Plasma protein was measured by refractometry (National Instrument, Baltimore, MD). Urine protein was determined on 24-h samples by precipitation with sulfosalicylic acid using albumin standards.
Histopathology evaluation. The right kidney was sectioned coronally, fixed in $10 \%$ phosphate-buffered formalin, and totally embedded in a paraffin block. Approximately three sections were cut from each block and stained with hematoxylin and eosin. Sections were evaluated for renal pathology using the following scoring system: 0 , normal kidney; $1+$, minimal focal tubulointerstitial injury (including tubular atrophy, dilation, and fibrosis); $2+$, moderate tubulointerstitial injury, involving multiple microscopic fields at $\times 100$; and $3+$, extensive tubulointerstitial injury, involving more than half of microscopic fields at $\times 100$. The observer was blinded to the codes indicating treatment.

Statistical analysis. The data are expressed as means $\pm \mathrm{SE}$. Data for the groups were compared using two-way ANOVA. Statistical significance was indicated by a value of $p<0.05$ or better.

\section{RESULTS}

Growth and adult blood pressure in runt offspring of normal pregnancies and their normal-sized littermates. The mean control birth weight for male rats was $6.38 \pm 0.12 \mathrm{~g}$; male runts weighed $5.46 \pm 0.13 \mathrm{~g}$. Likewise, the mean control birth weight for female rats was $6.31 \pm 0.15 \mathrm{~g}$, and female runts weighed $4.81 \pm 0.16 \mathrm{~g}$. Thus, in this study, birth weights of runts averaged $20 \pm 2 \%$ lower than those of their "normal birth weight" littermates. Body weights and blood pressures of runt offspring and their littermate controls are shown in Fig. 1. The weights of these animals were still reduced at the time of weaning. As a group, runts remained significantly smaller than their sex-matched controls at the time of study, although this difference failed to reach statistical significance when male and
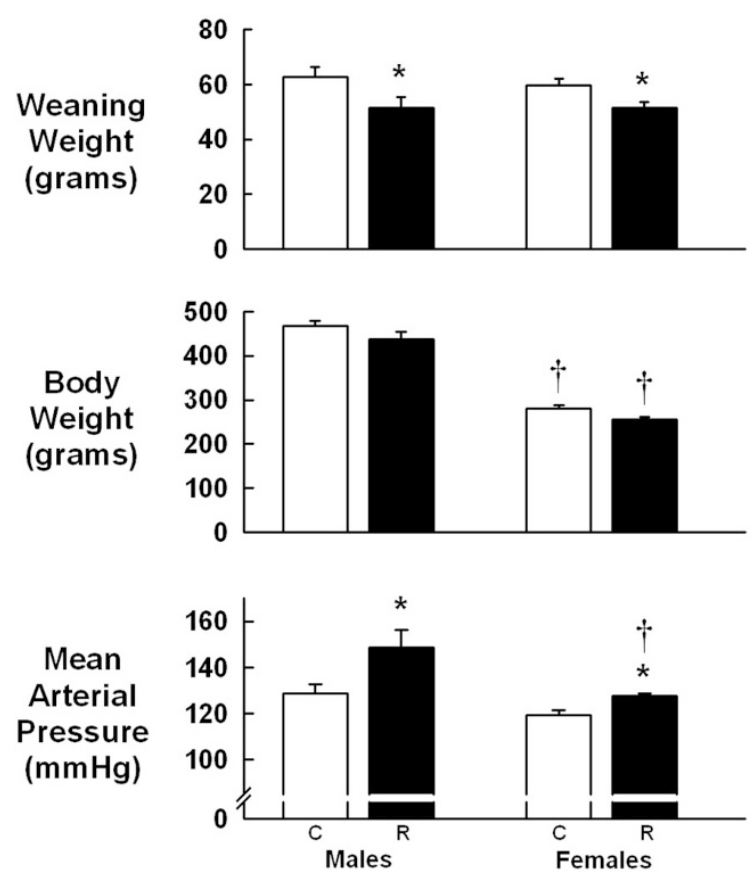

Figure 1. Body weights at weaning and in adulthood and blood pressure in normal and runt rat offspring. Mean $\pm \mathrm{SE}, n=5$ male pairs and $n=9$ female pairs. ${ }^{*} p<0.05$ vs sex-matched controls of normal birth weight; $\uparrow p<0.05 v s$ value in male rats. 
female rats were compared separately. Mean arterial pressure in conscious, chronically instrumented adult animals was significantly higher in the runts than in their littermate controls. The male runts tended to be more hypertensive than the female runts (i.e. a greater difference from controls), but this did not reach statistical significance $(p=0.06)$.

Renal function measurements in runt offspring and their normal-sized littermates. GFR, ERPF, and urine protein excretion are shown in Fig. 2. In both male and female rats, GFR and ERPF were not significantly different between runts and controls. However, GFR and ERPF were significantly lower in female than in male rats, as would be expected because of the differences in body weight. Urine protein excretion was higher in male runts than in their controls $(p=0.02)$ but was not different between female runts and controls. Hematocrit and plasma protein were not different between runts and controls (Table 1).
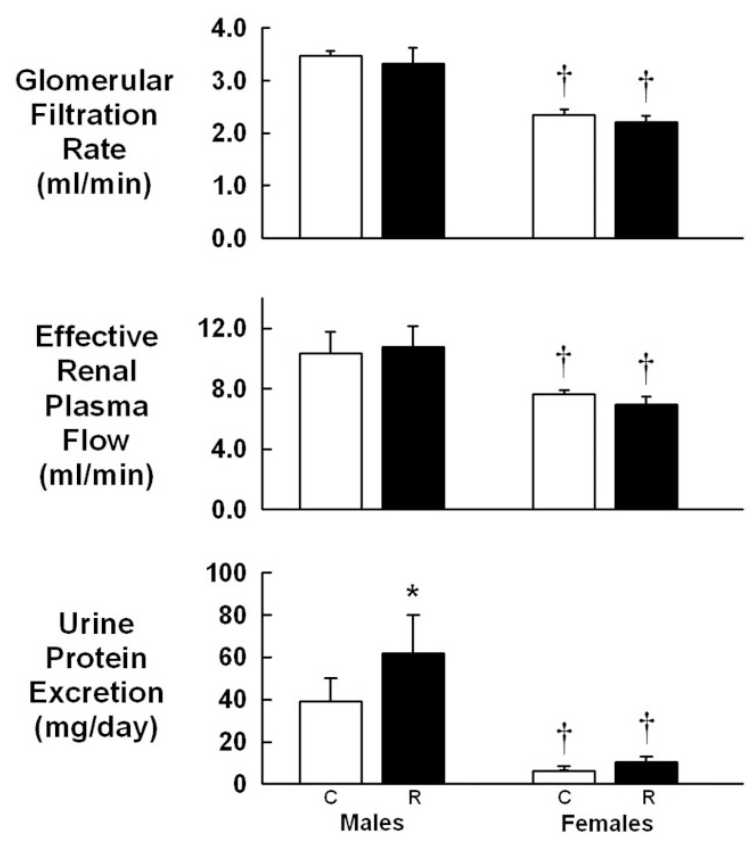

Figure 2. Renal function in normal and runt rat offspring. Mean $\pm \mathrm{SE}, n=$ 5 male pairs and $n=9$ female pairs. $* p<0.05$ vs sex-matched controls of normal birth weight; $\uparrow p<0.05$ vs value in male rats.
Adrenal and heart weights in runt offspring and their normal-sized littermates. Absolute adrenal weights were not different between runts and controls or between male and female rats. However, the adrenal-to-body weight ratio was significantly higher in runts than in their littermate controls (Table 1). This was true when male and female rats were grouped together but was significant only for female rats when the sexes were analyzed separately. The heart-to-body weight ratio tended to be increased in runts compared with controls, although this was statistically significant only in the male rats. The heart-to-body weight ratio was greater in female than in male rats in both controls and runts.

Renal histopathology in runt offspring and their normalsized littermates. The histology score in female runts was slightly although not significantly higher than in controls $(2.0$ \pm 0.3 , runts versus $1.3 \pm 0.5$, controls). In male rats, there was no difference in histology score between runts and controls ( 2.2 \pm 0.2 , runts versus $2.2 \pm 0.2$, controls).

\section{DISCUSSION}

Initially proposed almost two decades ago, the "fetal origins" hypothesis holds that variations in environmental factors before birth, factors that affect fetal growth, can cause permanent changes in the physiology and morphology of specific organ systems, thus programming an individual for an increased risk for various diseases later in life. Numerous studies have reported that human infants who are born small have an increased arterial blood pressure and associated cardiovascular risk in adulthood compared with larger infants (1-5). However, the conclusions of these studies and the degree to which they support the fetal origins hypothesis have recently been questioned (18). A number of animal models of prenatal programming are available, including maternal dietary protein or global food restriction, placental embolization, and ligation of the uterine artery. However, these models have been criticized because they may use maternal insults that, although effective in programming the offspring, are more severe insults than would normally be encountered by humans in Western society. The most important finding of the present study is that in intact rats on a normal, ad libitum diet, offspring that are naturally

Table 1. Organ weights, normalized renal function values, and blood values in normal and runt rat offspring

\begin{tabular}{|c|c|c|c|c|}
\hline & \multicolumn{2}{|c|}{ Males } & \multicolumn{2}{|c|}{ Females } \\
\hline & Control & Runt & Control & Runt \\
\hline Kidney wt (g) & $3.11 \pm 0.09$ & $2.98 \pm 0.21$ & $2.04 \pm 0.08 \dagger$ & $1.84 \pm 0.08 \dagger$ \\
\hline GFR/kidney wt $\left(\mathrm{mL} \cdot \min ^{-1} \cdot \mathrm{g}^{-1}\right)$ & $1.11 \pm 0.05$ & $1.11 \pm 0.07$ & $1.16 \pm 0.05$ & $1.20 \pm 0.07$ \\
\hline GFR/body wt $\left(\mathrm{mL} \cdot \min ^{-1} \cdot 100 \mathrm{~g}^{-1}\right)$ & $0.738 \pm 0.019$ & $0.770 \pm 0.041$ & $0.841 \pm 0.041$ & $0.862 \pm 0.038$ \\
\hline ERPF/kidney wt $\left(\mathrm{mL} \cdot \min ^{-1} \cdot \mathrm{g}^{-1}\right)$ & $3.32 \pm 0.51$ & $3.55 \pm 0.33$ & $3.76 \pm 0.10$ & $3.77 \pm 0.30$ \\
\hline ERPF/body wt $\left(\mathrm{mL} \cdot \min ^{-1} \cdot 100 \mathrm{~g}^{-1}\right)$ & $2.20 \pm 0.30$ & $2.48 \pm 0.23$ & $2.72 \pm 0.09$ & $2.71 \pm 0.19$ \\
\hline Adrenal/body wt ratio (\%) & $0.013 \pm 0.001$ & $0.014 \pm 0.001$ & $0.022 \pm 0.001 \dagger$ & $0.027 \pm 0.001 * \dagger$ \\
\hline Heart wt $(\mathrm{g})$ & $1.52 \pm 0.06$ & $1.57 \pm 0.09$ & $1.06 \pm 0.03 \dagger$ & $1.00 \pm 0.02 \dagger$ \\
\hline Heart/body wt ratio (\%) & $0.327 \pm 0.009$ & $0.369 \pm 0.010 *$ & $0.379 \pm 0.007 \dagger$ & $0.396 \pm 0.007$ \\
\hline Hematocrit $(\%)$ & $48 \pm 2$ & $47 \pm 2$ & $42 \pm 1 \dagger$ & $43 \pm 1 \dagger$ \\
\hline Plasma protein $(\mathrm{g} / \mathrm{dL})$ & $6.7 \pm 0.1$ & $6.8 \pm 0.1$ & $6.5 \pm 0.1$ & $6.6 \pm 0.1$ \\
\hline
\end{tabular}

$* p<0.05 v s$. sex-matched littermate controls.

$\dagger p<0.05 v s$. value in male rats. 
born small clearly have higher blood pressure in adult life than do their normal-birth-weight littermates. Thus, as has been reported in humans, it seems that in the rat, naturally occurring factors that influence growth in utero can also program the future blood pressure level. This finding supports the fetal origins hypothesis and indicates that prenatal programming is a more universal phenomenon that occurs in other species as well as in humans and does not require severe maternal dietary or environmental insults to occur.

We are aware of only one previous study that examined this (naturally occurring) phenomenon in animals. Poore et al. (15) studied the relationship between birth weight and arterial pressure at $3 \mathrm{mo}$ of age in piglets. These investigators were unable to show a statistically significant difference between blood pressures of animals that were classified as "low birth weight" (below the 95\% confidence interval of the mean for pups from all litters) and "high birth weight" (above the 95\% confidence interval of the mean). However, the mean blood pressure for "low birth weight" animals was $\sim 8 \mathrm{~mm} \mathrm{Hg}$ higher than the mean for "high birth weight" animals (15). Furthermore, these authors reported a statistically significant negative correlation between mean arterial pressure and birth weight in all piglets studied (15). Thus, although the results of this study in the pig were not as definitive as one might have hoped, they are generally consistent with our present findings in the rat.

Although the mechanisms for this fetal "programming" of adult blood pressure and other diseases are not completely understood, it is thought that fetal undernutrition may play an important role. Fetal undernutrition could in turn be caused by maternal undernutrition or by impairment of uteroplacental blood flow or nutrient exchange in an otherwise well-nourished mother. Indeed, as indicated above, current animal models of fetal programming include maternal dietary protein restriction or global food restriction $(6-8,11,19)$, as well as placental embolization, carunclectomy, and uterine artery ligation (all of which impair uteroplacental blood flow and/or nutrient exchange) (20-22). In the rat and other animals with a bicornate uterus, natural variations in fetal growth occur at least partially because of the somewhat complicated architecture of the vascular supply to the uterus and placenta (23). On the right side, a uterine arterial loop is supplied by the ovarian artery at the ovarian end of the horn and by the uterine artery at the cervical end, resulting in a reduced blood flow to the middle region of the uterine horn. Placentas from fetuses in the middle of the horns also tend to be smaller than those at the ends, as do the fetuses themselves. The architecture is similar on the left, except that the ovarian artery originates from the renal artery rather than the descending aorta. On this side, fetal weight and placental blood flow are highest at the cervical end and lowest at the ovarian end of the horn (23). Thus, in the rat, normal variations in fetal growth occur because of differences in nutrient availability to individual fetuses.

We have postulated that fetal undernutrition programs for offspring hypertension by suppressing the intrarenal reninangiotensin system during development, resulting in permanent changes in renal structure and function, including a reduced number of nephrons (7). In support of this postulate, we have shown that male offspring of protein-restricted mothers have reduced renal renin mRNA, renin, and angiotensin II levels in the newborn period and a reduced number of nephrons in adulthood (7). Furthermore, pharmacologic suppression of the renin-angiotensin system in the newborn period with losartan leads to a reduced number of nephrons and hypertension, and surgical reduction in the number of nephrons from birth also leads to adult hypertension, indicating a cause-and-effect relationship among these findings (12-14).

The mechanisms responsible for the hypertension in runt offspring in the present study are not clear. On the basis of our previous studies, it seems likely that nephron number may be reduced in runt offspring compared with their littermate controls, although we did not count nephrons in this study. One report suggests that birth weight is not related to nephron number in the rat; however, runts were specifically excluded from that study, and the birth weights of their "low" and "normal" birth weight groups were actually close (only a 7\% difference) (24). Impaired renal function may also lead to hypertension in animals that are small at birth. However, GFR was not significantly reduced in the runts in the present study compared with their controls, suggesting that if altered glomerular function plays a role, then it is more subtle than can be detected by these techniques. In rat offspring of modestly protein-restricted mothers, mean GFR was reduced by $\sim 10 \%$, although this also failed to reach statistical significance (7). We have found that in runt offspring of mothers that received a variety of other treatments (including dietary salt loading and protein restriction), the GFR per kidney or body weight was significantly reduced compared with their littermate controls (unpublished data). Thus, it is likely that reduced glomerular filtration contributed to the hypertension in those animals. The kidney normally undergoes compensatory hypertrophy and hyperfiltration in response to an initial loss of nephrons and their function, making functional changes as a result of small deficits in nephron number difficult to detect. Thus, reduced renal function may have also contributed in a more subtle way to the hypertension in the runt offspring of normal mothers in the present study. Impaired tubular function may also play a role in causing hypertension in runts; however, we did not measure tubular function in these studies.

In the present study, we took great care to acclimatize our animals to the study conditions, including restraint, before making measurements and to minimize other stressors such as unnecessary noise or temperature variations. Indeed, the animals frequently slept during the blood pressure measurements. However, it remains possible that stress may be a factor in revealing the differences in blood pressure between runt and control offspring. Indeed, one study suggested that the hypertension in male offspring of severely protein-restricted rat dams is greater during olfactory stress than under unstressed conditions (25). However, it seems that the remaining low to modest level of stress experienced by the animals in our present study is perhaps not unlike the levels of stress that humans undergo during normal day-to-day activity, possibly even strengthening this as a model of the human condition.

Another interesting finding of the present study is that the adrenal/body weight ratio was increased in female runt animals. This finding is consistent with a report in pigs indicating 
that the adrenal/body weight ratio at 3 mo of age is increased in animals of lower birth weight compared with those of higher birth weight (15). Changes in the hypothalamo-pituitaryadrenal axis have been suggested to play a role in programming for hypertension by fetal undernutrition (26), and it is possible that these alterations in relative adrenal size in runt animals in the present study also contribute to their hypertension. However, the male runts tended to be more hypertensive than the female runts, yet the adrenal/body weight ratio was not increased in male runts, suggesting that the hypothalamopituitary-adrenal axis may not play an important role in causing the increased blood pressure in runt animals.

Emerging evidence indicates that there are gender differences in fetal programming for adult hypertension. For example, we have found that modest maternal dietary protein restriction during pregnancy programs male offspring but not female offspring for hypertension; a more severe maternal protein restriction programs increased arterial pressure in both male and female offspring (7,11, Woods LL, Ingelfinger JI. Rasch R. Modest maternal protein restriction fails to program adult hypertension in female rats, submitted). Likewise, in a model of reduced nephron number from birth (neonatal uninephrectomy), male animals become more hypertensive and show renal damage earlier than do female animals $(13,14)$. Finally, in offspring of rats that were modestly food-restricted (fed $70 \%$ of the normal intake for the first $18 \mathrm{~d}$ of pregnancy), male rats became hypertensive at a younger age than did females (27). Thus, female gender seems to provide relative protection against programming for adult hypertension. Although it was not our intent in the present study to rigorously examine possible sex differences in runt animals, there are suggestions in our data that some sex differences may indeed be present. The elevation in blood pressure in male runts compared with controls was more than twice as great as the elevation in blood pressure in female runts. Although this sex difference did not reach statistical significance, it seems likely that it is real and would reach significance if the sample size were larger. Certainly a difference of this magnitude would be physiologically significant. Worse hypertension in male runts than in female runts would also fit with the finding that urine protein excretion was significantly higher in male runts than in male controls but not significantly different in female runts than in controls.

\section{CONCLUSION}

In summary, numerous studies have now shown an inverse relationship between birth weight (and other indices of fetal growth) and adult blood pressure in humans. The present study suggests that this may be a more universal phenomenon, possibly occurring in many, if not all, mammalian species. To date, all of the animal models of perinatal programming involve an experimental manipulation such as maternal dietary restriction or reduction of uterine blood flow. The availability of a naturally occurring animal model of this phenomenon, such as that provided by runt offspring in the rat, may broaden our possibilities for study of the physiologic and morphologic mechanisms responsible for the fetal origins of adult disease.

Acknowledgments. We thank Kathryn Parent and Melinda Davison for technical assistance.

\section{REFERENCES}

1. Barker DJ, Bull AR, Osmond C, Simmonds SJ 1990 Fetal and placental size and risk of hypertension in adult life. BMJ 301:259-262

2. Curhan GC, Chertow GM, Willett WC, Spiegelman D, Colditz GA, Manson JE, Speizer FE, Stampfer MJ 1996 Birth weight and adult hypertension and obesity in women. Circulation 94:1310-1315

3. Curhan GC, Willett WC, Rimm EB, Spiegelman D, Ascherio AL, Stampfer MJ 1996 Birth weight and adult hypertension, diabetes mellitus, and obesity in US men. Circulation 94:3246-3250

4. Law CM, de Swiet M, Osmond C, Fayers PM, Barker DJ, Cruddas AM, Fall CH 1993 Initiation of hypertension in utero and its amplification throughout life. BMJ 306:24-27

5. Thame M, Osmond C, Wilks RJ, Bennett FI, McFarlane-Anderson N, Forrester TE 2000 Blood pressure is related to placental volume and birth weight. Hypertension 35:662-667

6. Langley SC, Jackson AA 1994 Increased systolic blood pressure in adult rats induced by fetal exposure to maternal low protein diets. Clin Sci (Lond) 86:217-222

7. Woods LL, Ingelfinger JR, Nyengaard JR, Rasch R 2001 Maternal protein restriction suppresses the newborn renin-angiotensin system and programs adult hypertension in rats. Pediatr Res 49:460-467

8. Woodall SM, Johnston BM, Breier BH, Gluckman PD 1996 Chronic maternal undernutrition in the rat leads to delayed postnatal growth and elevated blood pressure of offspring. Pediatr Res 40:438-443

9. Benediktsson R, Lindsay RS, Noble J, Seckl JR, Edwards CR 1993 Glucocorticoid exposure in utero: new model for adult hypertension. Lancet 341:339-341

10. Levitt NS, Lindsay RS, Holmes MC, Seckl JR 1996 Dexamethasone in the last week of pregnancy attenuates hippocampal glucocorticoid receptor gene expression and elevates blood pressure in the adult offspring in the rat. Neuroendocrinology 64:412418

11. Woods LL, Weeks DA, Rasch R 2004 Programming of adult blood pressure by maternal protein restriction: role of nephrogenesis. Kidney Int 65:1339-1348

12. Woods LL, Rasch R 1998 Perinatal ANGII programs adult blood pressure, glomerular number, and renal function in rats. Am J Physiol 275:R1593-R1599

13. Woods LL 1999 Neonatal uninephrectomy causes hypertension in adult rats. Am J Physiol 276:R974-R978

14. Woods LL, Weeks DA, Rasch R 2001 Hypertension after neonatal uninephrectomy in rats precedes glomerular damage. Hypertension 38:337-342

15. Poore KR, Forhead AJ, Gardner DS, Giussani DA, Fowden AL 2002 The effects of birth weight on basal cardiovascular function in pigs at 3 months of age. J Physiol 539:969-978

16. Waugh WH 1977 Photometry of inulin and polyfructosan by use of a cysteine/ tryptophan reaction. Clin Chem 23:639-645

17. Brun C 1951 A rapid method for the determination of para-aminohippuric acid in kidney function tests. J Lab Clin Med 37:955-958

18. Huxley R, Neil A, Collins R 2002 Unravelling the fetal origins hypothesis: is there really an inverse association between birthweight and subsequent blood pressure? Lancet 360:659-665

19. Hanson MA, Hawkins P, Ozaki T, Steyn C, Matthews SG, Noakes D, Poston L 1999 Effects of experimental dietary manipulation during early pregnancy on cardiovascular and endocrine function in fetal sheep and young lambs. In: O'Brien PMS, Wheeler T, Barker DJP (eds) Fetal Programming: Influences on Development and Disease in Later Life. RCOG Press, London, pp 365-373

20. Persson E, Jansson T 1992 Low birth weight is associated with elevated adult blood pressure in the chronically catheterized guinea-pig. Acta Physiol Scand 145:195-196

21. Robinson JS, McMillen C, Edwards L, Erwich JJHM, Roberts C, Kind KL, Owens JA. The effect of maternal nutrition on growth and development before and after birth. In: O'Brien PMS, Wheeler T, Barker DJP (eds) Fetal Programming: Influences on Development and Disease in Later Life. RCOG Press, London, pp 217-230

22. Louey S, Cock ML, Stevenson KM, Harding R 2000 Placental insufficiency and fetal growth restriction lead to postnatal hypotension and altered postnatal growth in sheep. Pediatr Res 48:808-814

23. Even MD, Laughlin MH, Krause GF, vom Saal FS 1994 Differences in blood flow to uterine segments and placentae in relation to sex, intrauterine location and side in pregnant rats. J Reprod Fertil 102:245-252

24. Jones SE, Nyengaard JR, Flyvbjerg A, Bilous RW, Marshall SM 2001 Birth weight has no influence on glomerular number and volume. Pediatr Nephrol 16:340-345

25. Tonkiss J, Trzcinska M, Galler JR, Ruiz-Opazo N, Herrera VL 1998 Prenatal malnutrition-induced changes in blood pressure: dissociation of stress and nonstress responses using radiotelemetry. Hypertension 32:108-114

26. Phillips DI 2001 Fetal growth and programming of the hypothalamic-pituitaryadrenal axis. Clin Exp Pharmacol Physiol 28:967-970

27. Ozaki T, Nishina H, Hanson MA, Poston L 2001 Dietary restriction in pregnant rats causes gender-related hypertension and vascular dysfunction in offspring. J Physiol 530:141-152 